\title{
Insight Into the Permeation Barrier of Glued Langmuir- Blodgett Bilayers
}

\author{
Donald H. McCullough III, ${ }^{\dagger}$ Ruslan Grygorash, ${ }^{*}$ James T. Hsu ${ }^{\dagger}$ and Steven L. Regen ${ }^{*}$ \\ Departments of Chemistry and Chemical Engineering, Lehigh University, Bethlehem, Pennsylvania \\ 18015
}

SUPPORTING INFORMATION

\section{Experimental Section}

Materials. Unless stated otherwise, all reagents and chemicals were obtained from commercial sources and used without further purification. House-deionized water was purified using a Millipore Milli-Q-filtering system containing one carbon and two ion-exchange stages. The $\mathrm{pH}$ of the subphase was adjusted by addition of either aqueous $\mathrm{NaOH}$ or $\mathrm{HCl}$ solutions. Chloroform/trifluoroethanol (2.5/1, $\mathrm{v} / \mathrm{v}$ ), which was used as a spreading solvent for $\mathbf{3}$, was prepared from HPLC grade Burdick and Jackson solvents; 2 was spread as a chloroform solution. Poly(acrylic acid) (PAA, Mw=240,000) was purchased from Aldrich and used as obtained. Poly[1-(trimethylsilyl)-1-propyne] was a gift from Air Products and Chemicals. Methyl perfluoroundecanoate was purchased from Oakwood Prod., Inc., West Columbia, South Carolina, and used without further purification. A Nima 612D film balance (Nima Technologies, Coventry England) was used for all monolayer experiments; ${ }^{1} \mathrm{H}$ NMR spectra were recorded on BRUKER DRX 500 spectrometer.

$\mathbf{N}$-[2-(Dimethylamino)ethyl]-perfluoroundecanoic acid amide. $\quad N, N$-Dimethylethylenediamine $(1.15 \mathrm{~g}, 13.0 \mathrm{mmol})$ was added, dropwise, to solution of methyl perfluoroundecanoate $(5 \mathrm{~g}, 8.7 \mathrm{mmol})$ in $25 \mathrm{~mL}$ of THF. After refluxing the mixture for $5 \mathrm{~h}$, the solvent was removed under reduced pressure 
and the residue was purified by crystallization from cyclohexane to give $\mathrm{N}$-[2-(dimethylamino)ethyl]perfluoroundecanoic acid amide $\left(4.77 \mathrm{~g} 87 \%\right.$ ) as a colorless solid having $\mathrm{mp} 70-72^{\circ} \mathrm{C}$ and ${ }^{1} \mathrm{H}$ NMR $\left(\mathrm{CF}_{3} \mathrm{CO}_{2} \mathrm{D}\right) \delta \mathrm{ppm}: 3.95(\mathrm{t}, 2 \mathrm{H}) ; 3.56(\mathrm{t}, 2 \mathrm{H}) ; 3.11(\mathrm{~s}, 6 \mathrm{H})$.

\section{1,2,4,5-Tetrakis[( $N$-(perfluoroundecanoamidoethyl)- $N, N$-dimethylammonium)methyl]benzene}

tetrabromide (3). To a solution of 1,2,4,5-tetrakis(bromomethyl)benzene (100 mg, $0.22 \mathrm{mmol}$ ) in 15 mL of $\mathrm{CH}_{3} \mathrm{CN}$ (HPLC grade) was added $\mathrm{N}$-[2-(dimethylamino)ethyl]-perfluoroundecanoic acid amide (845 mg, $1.32 \mathrm{mmol}$ ). After stirring for $24 \mathrm{~h}$ at $75^{\circ} \mathrm{C}$, the reaction mixture was cooled to room temperature and the solid that formed was isolated by filtration Subsequent recrystallization from $\mathrm{CF}_{3} \mathrm{CH}_{2} \mathrm{OH} / \mathrm{THF}(1 / 1, \mathrm{v} / \mathrm{v})$ afforded $550 \mathrm{mg}(83 \%)$ of 3 as a colorless solid having ${ }^{1} \mathrm{H} \mathrm{NMR}\left(\mathrm{CF}_{3} \mathrm{CO}_{2} \mathrm{D}\right)$ $\delta$ ppm: $8.76(\mathrm{~s}, 2 \mathrm{H}) ; 5.37(\mathrm{~s}, 8 \mathrm{H}) ; 4.20-4.14(\mathrm{~m}, 16 \mathrm{H}) ; 3.40(\mathrm{~s}, 24 \mathrm{H})$. Anal. Calcd. for $\mathrm{C}_{70} \mathrm{H}_{54} \mathrm{Br}_{4} \mathrm{~F}_{84} \mathrm{~N}_{8} \mathrm{O}_{4}: \mathrm{C}, 28.15 ; \mathrm{H}, 1.82 ; \mathrm{F}, 53.43 ; \mathrm{N}, 3.75$. Found: C, 27.75; H, 1.99; F, 52.95; N, 3.92.

N-[2-(Dimethylamino)ethyl]-undecanoic acid amide. Undecanoic acid (1.5 g, $8 \mathrm{mmol})$ and $\mathrm{N}$ hydroxysuccinimide $(1.43 \mathrm{~g}, 12.5 \mathrm{mmol})$ were dissolved in dry THF $(15 \mathrm{~mL})$. To the cooled solution $\left(0^{\circ} \mathrm{C}\right)$, DCC (2.16 g. $\left.10.5 \mathrm{mmol}\right)$ was added, and the reaction mixture stirred for $12 \mathrm{~h}$ at $\mathrm{rt}$ The urea that was formed was then removed by filtration, and $N, N$-dimethylethylenediamine $(1.94 \mathrm{~mL}$, $17.5 \mathrm{mmol}$ ) was added, dropwise, to the filtrate. After stirring for $6 \mathrm{~h}$ at $\mathrm{rt}$, the solvent was removed under reduced pressure and the residue dissolved in $100 \mathrm{ml}$ of $\mathrm{CHCl}_{3}$. This organic solution was washed, sequentially, with $5 \% \mathrm{NaHCO}_{3}(2 \times 50 \mathrm{~mL}), \mathrm{H}_{2} \mathrm{O}(1 \times 50 \mathrm{~mL})$, and brine $(1 \times 50 \mathrm{~mL})$ and dried over anhydrous $\mathrm{Na}_{2} \mathrm{SO}_{4}$. Removal of solvent under reduced pressure, followed by purification via column chromatography [silica gel, $\mathrm{CHCl}_{3} / \mathrm{MeOH}(1 / 1, \mathrm{v} / \mathrm{v})$ ] afforded $1.65 \mathrm{~g}(80 \%)$ of $\mathrm{N}-[2-$ (dimethylamino)ethyl]-undecanoic acid amide as a colorless solid having $\mathrm{R}_{\mathrm{f}}=0.45$ and ${ }^{1} \mathrm{H}$ NMR $\left(\mathrm{CDCl}_{3}\right) \delta$ ppm: $6.00(\mathrm{~s}, 1 \mathrm{H}) ; 3.29(\mathrm{~m}, 2 \mathrm{H}) ; 2.37(\mathrm{t}, 2 \mathrm{H}) ; 1.59(\mathrm{~s}, 2 \mathrm{H}) ; 1.23(\mathrm{~s}, 16 \mathrm{H}) ; 0.84(\mathrm{~s}, 3 \mathrm{H})$.

\section{1,2,4,5-Tetrakis[( $N$-(undecanoamidoethyl)- $N, N$-dimethylammonium)methyl]benzene}

tetrabromide (2). To a solution of 1,2,4,5-tetrakis(bromomethyl)benzene (460 $\mathrm{mg}, 1.02 \mathrm{mmol}$ ) in 50 $\mathrm{mL}$ of $\mathrm{CH}_{3} \mathrm{CN}$ was added $\mathrm{N}$-[2-(dimethylamino)ethyl]-undecanoic acid amide (1.65 $\left.\mathrm{g}, 6.45 \mathrm{mmol}\right)$. 
After stirring for $12 \mathrm{~h}$ at $75^{\circ} \mathrm{C}$, the mixture was cooled to $\mathrm{rt}$, and the resulting solid removed by filtration. Subsequent recrystallization, using $15 \mathrm{~mL}$ of isopropanol/acetone (9/2, v/v), afforded $1.19 \mathrm{~g}$ (96\%) of 2 as a white solid having ${ }^{1} \mathrm{H}$ NMR $\left(\mathrm{CF}_{3} \mathrm{CO}_{2} \mathrm{D}\right) \delta$ ppm: $8.53(\mathrm{~s}, 2 \mathrm{H}) ; 5.24(\mathrm{~s}, 8 \mathrm{H}) ; 4.08(\mathrm{~s}, 8 \mathrm{H})$; $3.97(\mathrm{~s}, 8 \mathrm{H}) ; 3.31(\mathrm{~s}, 24 \mathrm{H}) ; 2.44(\mathrm{~s}, 8 \mathrm{H}) ; 1.60(\mathrm{~s}, 8 \mathrm{H}) ; 1.28(\mathrm{~s}, 56 \mathrm{H}) ; 0.76(\mathrm{~s}, 12 \mathrm{H})$. Anal. Calcd. for $\mathrm{C}_{70} \mathrm{H}_{138} \mathrm{Br}_{4} \mathrm{~N}_{8} \mathrm{O}_{4}:$ C, 56.98; H, 9.43; N, 7.59. Found: C, 56.29; H, 9.23; N, 7.51.

Surface Pressure-Area Isotherms. Surface pressure-area isotherms were recorded using a Nima film balance that was equipped with a computerized data acquisition station. All isotherms were measured at $25^{\circ} \mathrm{C}$. Before addition to the film balance, the surface of the water was removed via aspiration in order to remove surface-active contaminants. All surfactant solutions were spread onto the aqueous subphase, having a surface area of ca. $400 \mathrm{~cm}^{2}$, using a gas-tight $500 \mu \mathrm{L}$ Hamilton syringe. The concentration of these surfactant solutions was typically $0.2 \mathrm{mg} / \mathrm{mL}$. Exact concentrations were determined by direct weighing of aliquots after evaporation of solvent using a Cahn 27 electrobalance. In all cases, spreading solvents were allowed to evaporate for at least 30 min prior to compression, using a compressing speed of $25 \mathrm{~cm}^{2} / \mathrm{min}$.

Surface Viscosity Measurements. For surface viscosity experiments, a home-built canal viscometer (192 mm $\times 40 \mathrm{~mm}$ solid Teflon block, having a centrally located $6.0 \mathrm{~mm}$ slit) was placed in front of the compressing barrier and the monolayer was compressed at a rate of $25 \mathrm{~cm}^{2} / \mathrm{min}^{16}$ Compressions were stopped when a target pressure of $20 \mathrm{dyn} / \mathrm{cm}$ was reached. The resulting monolayer was then allowed to equilibrate at this pressure for $1 \mathrm{~h}$. After this time, the moving barrier was expanded at the maximum speed of $120 \mathrm{~cm}^{2} / \mathrm{min}$, leaving the canal viscometer at its original position. The resulting surface pressure was then recorded as a function of time. The rate of surface pressure decrease was taken as a measure of the relative surface viscosity of the monolayer.

Silylated Silicon Wafers. Silicon wafers (WaferNet, Inc., San Jose, CA) were cut into $15 \times 25 \mathrm{~mm}$ pieces and were immersed in concentrated $\mathrm{H}_{2} \mathrm{SO}_{4}$ and $30 \% \mathrm{H}_{2} \mathrm{O}_{2}\left(70 / 30\right.$, v/v) at $70^{\circ} \mathrm{C}$ for 4 h. Caution: "piranha solution" reacts violently with many organic materials and should be handled with great care. 
The wafers were then rinsed with distilled water, dried under a stream of nitrogen, and immersed in a 10 $\mathrm{mM}$ anhydrous hexane solution of $n$-octadecyltrichlorosilane (OTS) for $30 \mathrm{~min}$ at room temperature. ${ }^{18 \mathrm{~h}}$ The wafers were then rinsed with hexane and chloroform. The ellipsometric film thickness of the OTS layer was $2.6 \pm 0.1 \mathrm{~nm}$.

Ellipsometry Measurements. Ellipsometry measurements were made using an automatic null ellipsometer (Rudolph Auto-EL III), equipped with a helium-neon laser $(\lambda=632.8 \mathrm{~nm})$ that was set at an incident angle of $70^{\circ}$. Measurements were taken at four different regions along the surface of each sample and the mean and the standard deviations were calculated. Film thicknesses were determined using the manufacturer's program, assuming a refractive index for the silicon oxide layer of 1.465 , and a refractive index of 1.410 for the surfactant and polymer layers.

Fabrication of Composite Membranes and Gas Permeation Measurements. The PTMSP membranes (ca. $30 \mu \mathrm{m}$ thick) that were used as supports were prepared by casting procedures similar to those previously described. ${ }^{16}$ The deposition of unglued and glued lipid bilayers was made by conventional Langmuir-Blodgett (LB) methods using a single down-trip followed by a single up-trip. The dipping speed that was used for each monolayer transfer was $2 \mathrm{~mm} / \mathrm{min}$. Each composite membrane was allowed to remain in the laboratory ambient (clean room) for a minimum of $12 \mathrm{~h}$ prior to gas permeation measurements. Gas permeation measurements were made with a home-built stainless steel apparatus. ${ }^{16}$ 